OPEN ACCESS

Edited by:

Matteo Bolcato,

University of Padua, Italy

Reviewed by:

Guido Pelletti,

University of Bologna, Italy

Matteo Moretti,

University of Pavia, Italy

${ }^{*}$ Correspondence:

Tijana Serafimovska

serafimovskatijana@gmail.com

Specialty section:

This article was submitted to Family Medicine and Primary Care,

a section of the journal

Frontiers in Medicine

Received: 17 August 2021 Accepted: 24 September 2021

Published: 15 November 2021

Citation:

Serafimovska T, Stefanovski S, Erler J, Keskovski Z, Stefkov G, Mitevska M,

Darkovska Serafimovska M, Balkanov $T$ and Tonic Ribarska J (2021) Does Cannabis Extract Obtained From Cannabis Flowers With Maximum Allowed Residual Level of Aflatoxins and Ochratoxin a Have an Impact on Human Safety and Health? Front. Med. 8:759856.

doi: 10.3389/fmed.2021.759856

\section{Does Cannabis Extract Obtained From Cannabis Flowers With Maximum Allowed Residual Level of Aflatoxins and Ochratoxin a Have an Impact on Human Safety and Health?}

\author{
Tijana Serafimovska ${ }^{1 *}$, Sasho Stefanovski ${ }^{2}$, Joachim Erler ${ }^{3}$, Zlatko Keskovski ${ }^{2}$, \\ Gjoshe Stefkov ${ }^{1}$, Marija Mitevska ${ }^{2}$, Marija Darkovska Serafimovska ${ }^{4}$, Trajan Balkanov ${ }^{5}$ \\ and Jasmina Tonic Ribarska ${ }^{1}$ \\ ${ }^{1}$ Faculty of Pharmacy, University Ss. Cyril and Methodius, Skopje, North Macedonia, ${ }^{2}$ NYSK Holdings, Company for \\ Growing, Extraction and Producing of Pharmaceutical Dosage Forms of Medical Cannabis, Skopje, North Macedonia, \\ ${ }^{3}$ Diapharm GmbH \& Co. KG, Münster, Germany, ${ }^{4}$ Faculty of Medical Sciences, University Goce Delcev, Shtip, \\ North Macedonia, ${ }^{5}$ Department of Pharmacology and Toxicology, Faculty of Medicine, University Ss. Cyril and Methodius, \\ Skopje, North Macedonia
}

\begin{abstract}
Aim: The aim of this study was to investigate whether the cannabis extract obtained from cannabis flowers that contain the maximum allowed level of mycotoxins affects human safety and health. For that purpose, a novel liquid chromatography with tandem mass spectrometry (LC/MS/MS) method was developed and validated for the determination of aflatoxins and ochratoxin $\mathrm{A}(\mathrm{Och} \mathrm{A})$ in cannabis extracts to demonstrate that this analytical method is suitable for the intended experimental design.
\end{abstract}

Methods: Experimental design was done by adding maximum allowed concentration of aflatoxins (B1, B2, G1, G2) and OchA according to the European Pharmacopeia related to cannabis flowers. The concentration of aflatoxins and OchA was determined using the same LC/MS/MS analytical method in the starting material (dry flower) before preparing the spiked sample and after obtaining decarboxylated extract with ethanol $96 \%$.

Results: The results obtained indicate that aflatoxins and OchA, primarily added to the cannabis dried flowers, were also determined into the obtained final extract in amounts much higher $(\mathrm{m} / \mathrm{m})$ than in the starting plant material.

Conclusion: With this experiment, we have shown that mycotoxins, especially aflatoxins, which are extremely toxic secondary metabolites, can reach critical values in cannabis extracts obtained from dry cannabis flowers with the maximum allowed quantity of mycotoxins. This can pose a great risk to consumers and their health especially to those with compromised immune systems.

Keywords: mycotoxins, aflatoxins, ochratoxin A, determination liquid chromatography with tandem mass spectrometry (LC/MS/MS), cannabis extracts 


\section{INTRODUCTION}

Medicinal products based on Cannabis sativa L. (Cannabaceae) in traditional medicine, have been used for thousands of years in the treatment of various diseases (1). Although, there is a lack of evidence-based medical information that can prove the potential benefit of the therapy with medicinal cannabis preparations, recently, an increasing number of pharmacists have issued cannabis preparations to individual patients prescribed by their physicians (2).

To obtain cannabis-based preparations, standardized concentrated cannabinoid extracts, produced by a suitable extraction process of cannabinoids from cannabis flowers are used (2). The safety of the flowers as a starting material, in this case, is the most significant for human safety and health. Since there is no monograph in the European Pharmacopeia (Ph.Eur.) for quality testing of cannabis flowers, currently a revised monograph for cannabis flower (cannabis floss), published in the German Pharmacopeia 2018 (3), by the Federal Institute for Drugs and Medical Devices (BfArM) has instructed the obligatory procedure for quality testing of cannabis flowers in the European Union (4). However, a variety of herbal monographs are listed under the general monographs in Ph.Eur.: herbal drugs, herbal drug extracts, and herbal drug preparations. These general monographs are created to cover products and quality parameters, which are not mentioned in the individual monographs. Therefore, it is necessary to apply the individual monograph always in combination with these quality requirements (5).
According to the Guideline on specifications: test procedures and acceptance criteria for herbal substances (6), mycotoxins [aflatoxins, ochratoxin A (OchA)] are considered as impurities (contaminants) that can occur in the final extracts from starting materials (herbal drugs). In reference to this, Ph.Eur. gives the maximum allowed limits of these impurities (aflatoxins, as per Ph.Eur. 2.8.18 and OchA, as per Ph.Eur. 2.8.22) in herbal drugs.

\section{Impact of Mycotoxins on Human Safety and Health}

Mycotoxins (aflatoxins and OchA) are secondary toxic metabolites, obtained primarily from fungal species (Penicillium and Aspergillus). Fungi and their metabolites contaminate the raw materials usually used in the preparation of products for human use (7). The presence of these contaminants in products for human use can cause various acute and chronic effects on human safety and health (8).

Aflatoxins (Figure 1) are extremely toxic secondary metabolites. According to their chemical structures, they are generally categorized into two groups: the difurocouma rocyclopentenone group (aflatoxin B1 and B2) and the dif urocoumarolactone group (aflatoxin G1 and G2). The most toxic, carcinogenic, and mutagenic among all the aflatoxins is aflatoxin $\mathrm{B} 1$ (AfB1). Humans are mostly infected by direct ingestion (consuming) of infected herbal drugs, food, or herbal preparations (9).

Mycotoxins are metabolized in the liver, and microorganisms in the digestive tract $(10,11)$. AfB1 itself is not carcinogenic,<smiles>COc1cc2c(c3oc(=O)c4c(c13)CCC4=O)C1C=COC1O2</smiles>

Aflatoxin B1<smiles>COc1cc2c(c3oc(=O)c4c(c13)CCC4=O)C1C=COC1O2</smiles>

Aflatoxin G1<smiles>COc1cc2c(c3oc(=O)c4c(c13)CCC4=O)C1CCOC1O2</smiles>

Aflatoxin B2<smiles>COc1cc2c(c3oc(=O)c4c(c13)CCC4=O)C1C=COC1O2</smiles>

Aflatoxin G2

FIGURE 1 | Structures of aflatoxins. 


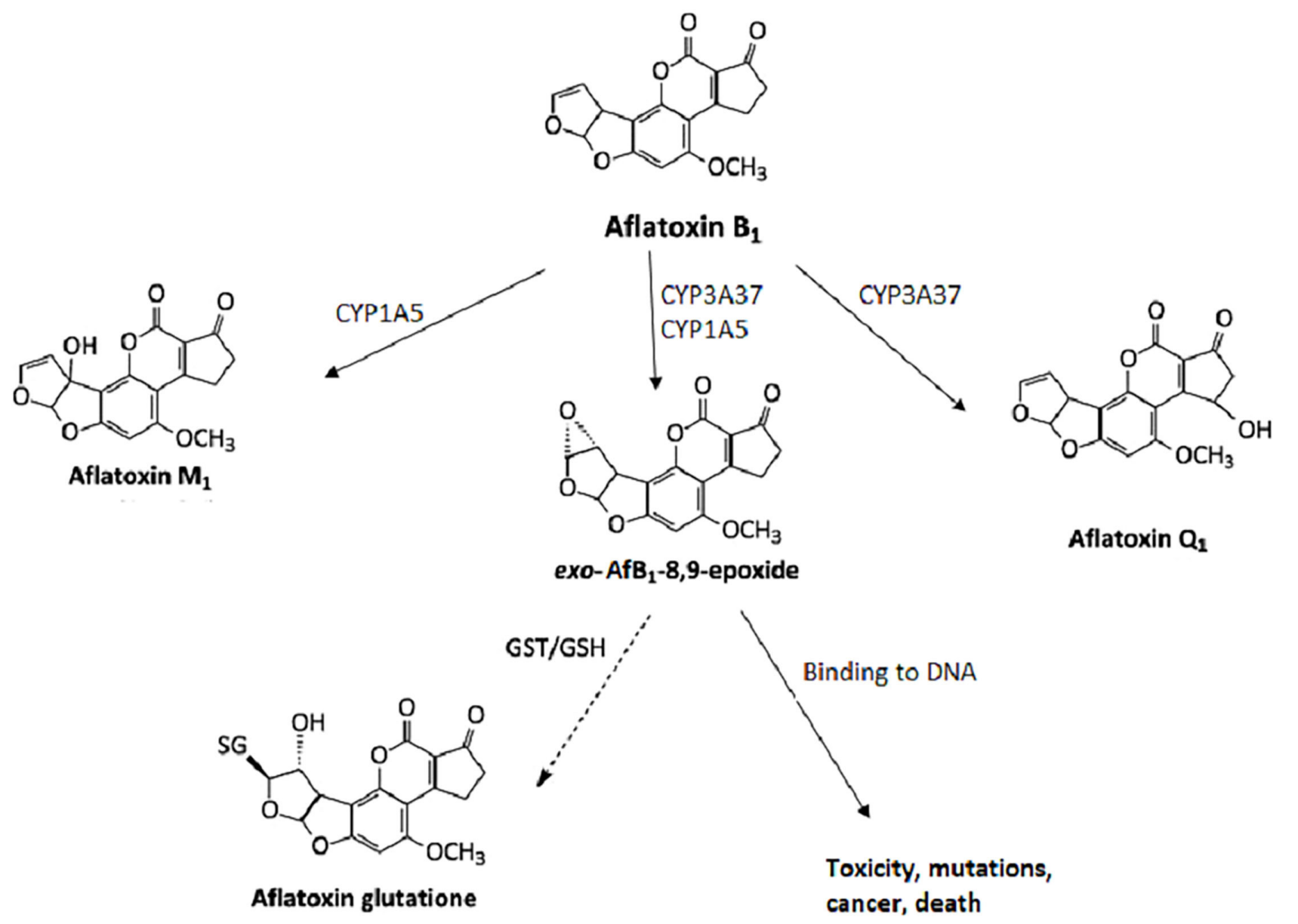

FIGURE 2 | Metabolism of aflatoxin B1 in hepatocytes.

but in the human body, it is metabolized into carcinogenic metabolites. All enzymes necessary for the bioactivation of AfB1 are present in the nuclear envelope of the hepatocytes. The mono-oxygenase system in microsomes can transform the AfB1 into aflatoxin M1 (AfM1), aflatoxin Q1 (AfQ1), and exo-AfB18,9-epoxide (Figure 2) which can bind to deoxyribonucleic acid (DNA) and causes cytotoxicity, DNA damage, chromosomal anomalies, gene mutation, and cell transformation by attacking the nucleophilic hetero-atoms such as oxygen and nitrogen in the organic bases of nucleic acids and forming a strong covalent bond to the DNA (9).

Specific effects of Aflatoxins on human safety and health can be classified into two groups such as chronic toxicity and acute toxicity.

Carcinogenicity, hepatotoxicity, nephrotoxicity, and endocrine disorders have been related to chronic exposure to low levels of mycotoxins $(12,13)$. In some cases, allergic reactions, immune diseases, reproductive deficiencies, fetal alterations, and death, have also been related to chronic exposure to mycotoxins (14). The health risks associated with mycotoxin exposure arise from their toxicity and depend on the type of toxin, its metabolism, the immune system, and the health status of the exposed individual (15). Due to the carcinogenic risk associated with the mycotoxins, the International Agency for Research on Cancer (IARC) has evaluated and classified mycotoxins as carcinogenic to humans (Group 1), possibly carcinogenic to humans (Group 2B), or not classifiable as to its carcinogenicity to humans (Group 3), based on sufficient experimental data (16).

The main target organ for toxicity, mutagenicity, and carcinogenicity is the liver (17).

Ochratoxin A (Figure 3) is a powerful mycotoxin, responsible for chronic toxicity, such as nephrotoxicity, hepatotoxicity, teratogenicity, and immunotoxicity to humans (18). There are several in vivo and in vitro studies published regarding nephrotoxicity and hepatotoxicity of OchA, due to diverse metabolites of OchA, but the exact mechanism of toxicity of this mycotoxin is still unclear $(19,20)$.

Therefore, the aim of this study was to investigate whether the cannabis extract obtained from cannabis flowers that contain the maximum allowed level of mycotoxins affects human safety and health. There are many recently published manuscripts related 


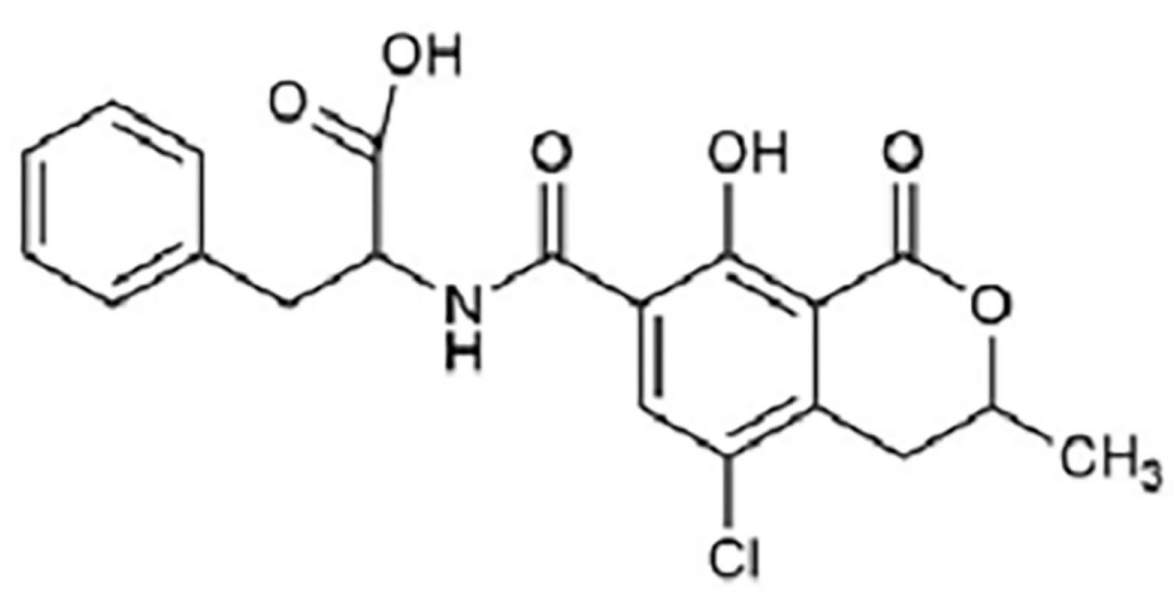

FIGURE 3 | Structure of Ochratoxin A.

to quantification techniques for the determination of mycotoxins in cannabis flower and cannabis extracts, inapplicable for the equipment we used $(21,22)$. For that reason, a novel LC/MS/MS method was developed and validated for the determination of aflatoxins and OchA in cannabis extracts to demonstrate that this analytical method is suitable for the intended experimental design, thus, achieving the set goal.

\section{MATERIALS AND METHODS}

\section{Chemicals and Regents}

Liquid standards of AfB1 Cat.No.TSL-104-10, aflatoxin B2 (AfB2) Cat.No.TSL-105-10, aflatoxin G1 (AfG1) Cat.No.TSL106-10, aflatoxin G2 (AfG2) Cat.No.TSL-107-10, and OchA Cat.No.TSL-504-5 were supplied by R-Biopharm (Germany). Other chemicals and reagents used in this study were LC/MS grade provided by Fisher Chemicals (UK).

Immunoaffinity columns (IAC) were obtained from RBiopharm (Germany), Cat. No. RBRP112B.

\section{Apparatus}

Liquid chromatography was performed on LC/MS/MS system (LC - 30AD series) equipped with a binary pump, vacuum degasser, standard autosampler, column compartment, and MS/MS detector (8045 series) from Shimadzu (Japan).

\section{Chromatographic Conditions}

The separation was performed using a gradient method and reversed-phase Raptor Biphenyl LC column (100 x $2.1 \mathrm{~mm}$, particle size $2.7 \mu \mathrm{m}$, Cat.No.980-18088) that provide the best separation characteristics, coupled with Raptor Biphenyl EXP guard column cartridge ( $5 \times 2.1 \mathrm{~mm}$, particle size $2.7 \mu \mathrm{m}$, cat.No.9309A0252) from Restek (USA). The choice of solvent for the preparation of standard solutions and extraction of mycotoxins (aflatoxins and OchA) from cannabis floss and extracts was made to eliminate the isobaric interferences resulting in spiked samples. It was determined that an extraction solvent of
TABLE 1 | Analytical conditions for analysis of aflatoxins and ochratoxin A (gradient method).

\begin{tabular}{|c|c|c|c|}
\hline Column & \multicolumn{3}{|c|}{$\begin{array}{l}\text { Raptor Biphenyl } 100 \mathrm{~mm} \times 2.1 \mathrm{~mm} \text {, particle size } 2.7 \mu \mathrm{m} \text {, } \\
\text { (Cat.No.980-18088) }\end{array}$} \\
\hline Guard column & \multicolumn{3}{|c|}{$\begin{array}{l}\text { Raptor Biphenyl EXP Guard Column Cartridge } 2.7 \mu \mathrm{m}, 5 \\
\times 2.1 \mathrm{~mm} \text { (cat.\# 9309A0252) }\end{array}$} \\
\hline Mobile phase A & \multicolumn{3}{|c|}{$5 \mathrm{mM}$ ammonium formate in water with $0.1 \%$ formic acid } \\
\hline Mobile phase $B$ & \multicolumn{3}{|c|}{$\begin{array}{l}5 \mathrm{mM} \text { ammonium formate in methanol with } 0.1 \% \text { formic } \\
\text { acid }\end{array}$} \\
\hline \multirow[t]{11}{*}{ Time program } & Time (min.) & Flow (mL/min.) & $\% \mathrm{~B}$ \\
\hline & 2.20 & 0.45 & 30 \\
\hline & 2.40 & 0.45 & 50 \\
\hline & 8.20 & 0.45 & 70 \\
\hline & 11.20 & 0.45 & 75 \\
\hline & 12.20 & 0.45 & 90 \\
\hline & 12.60 & 0.45 & 90 \\
\hline & 12.61 & 0.45 & 75 \\
\hline & 13.20 & 0.45 & 75 \\
\hline & 13.21 & 0.45 & 30 \\
\hline & 16 & 0.45 & 30 \\
\hline Oven temp. & \multicolumn{3}{|c|}{$40^{\circ} \mathrm{C}$} \\
\hline Sample temp. & \multicolumn{3}{|c|}{$15^{\circ} \mathrm{C}$} \\
\hline Inj. volume & \multicolumn{3}{|c|}{$10 \mu \mathrm{L}$} \\
\hline MS/MS & \multicolumn{3}{|c|}{ Shimadzu LCMS-8045 } \\
\hline Ion mode & \multicolumn{3}{|c|}{ ESI+ } \\
\hline
\end{tabular}

50:50 = water: methanol with $0.1 \%$ formic acid results in samples (extracts) with removed isobaric interferences.

The mobile phase contains a mixture of $5 \mathrm{mM}$ ammonium formate in water with $0.1 \%$ formic acid and $5 \mathrm{mM}$ ammonium formate in methanol with $0.1 \%$ formic acid and a flow rate of $0.45 \mathrm{ml} / \mathrm{min}$ gave the best results. Analytical conditions for the gradient method are given in Table 1. The injection volume of samples was $10 \mu \mathrm{l}$. 
TABLE 2 | Analyte transitions.

\begin{tabular}{|c|c|c|c|}
\hline Analyte & Precursor Ion & Product Ion (Quantifier) & Product Ion (Qualifier) \\
\hline Aflatoxin G2 & 331.0 & 189.2 & 313.2 \\
\hline Aflatoxin G1 & 329.0 & 200.2 & 243.2 \\
\hline Aflatoxin B2 & 315.1 & 287.2 & 243.2 \\
\hline Aflatoxin B1 & 312.9 & 285.2 & 241.2 \\
\hline Ochratoxin A & 404.1 & 239.1 & 358.2 \\
\hline
\end{tabular}

Water: methanol $=50: 50(\mathrm{~V} / \mathrm{V})$ with $0.1 \%$ formic acid was used for the preparation of standard solutions and extraction of mycotoxins (aflatoxins and OchA) from cannabis flowers and extracts.

Chromatographic data were analyzed using LabSolution software from Shimadzu (Japan), following the requirements for chromatographic analysis.

Analyte transitions are given in Table 2.

\section{Sample Preparation}

About $2 \mathrm{~g}$ of sample (ground flowers or extract) was weighed out in a $50 \mathrm{ml}$ centrifuge tube and then a $15 \mathrm{ml}$ mixture of methanol: water $(80: 20)$ was added to the tube. The mixture was shaken vigorously for $60 \mathrm{~min}$ using the rotation shaker $(70 \mathrm{rpm} / \mathrm{min})$ and then centrifuged at 4,000 rpm for $15 \mathrm{~min}$. About $6 \mathrm{ml}$ of the supernatant was transferred to a new tube containing $20 \mathrm{ml}$ of $2 \%$ Tween wash buffer in phosphate-buffered saline (PBS) and mixed well. A total of $26 \mathrm{ml}$ of the diluted extract was passed through the IAC AOZON at a rate of 1 drop per second until air came through the column (it is important that the flow rate does not exceed 1 drop per second). The column was washed with three portions of $15 \mathrm{ml}$ water (MS grade). Finally, the column was washed with $1 \mathrm{ml}$ of methanol. That $1 \mathrm{ml}$ is then diluted with $1 \mathrm{ml} 0.2 \%$ formic acid. The sample solutions before injection in the system were filtered using a membrane filter $(0.2 \mu \mathrm{m}$ pore size $)$.

\section{Standard Solutions and Calibration Curves}

Working calibration solutions containing AflB1, AflB2, AflG1, and AflG2 were prepared from $0.1-5 \mu \mathrm{g} / \mathrm{L}$ in 50:50 water: methanol with $0.1 \%$ formic acid and for OchA 1-50 $\mu \mathrm{g} / \mathrm{L}$ in 50:50 water: methanol with $0.1 \%$ formic acid.

Due to the influence of the matrix on the result (difference in the slope of the curve between the standard prepared in methanol water 50:50 with $0.1 \%$ formic acid and the standard prepared in the matrix), the calibration curve was made in a matrix.

\section{Validation of the Method}

The proposed method was validated according to the guidelines set by the International Conference of Harmonization for validation of analytical methods and the Directive 96/23/EC considering the performance of analytical methods and the interpretation of results $(23,24)$.

\section{Recovery Studies}

To establish the accuracy of the proposed method, recovery experiments were carried out by adding the known amounts of
TABLE 3 | Characteristics of the linear regression analysis.

\begin{tabular}{|c|c|c|c|c|c|}
\hline & AfG2 & AfG1 & AfB2 & AfB1 & OchA \\
\hline Linearity range $(\mu \mathrm{g} / \mathrm{L})$ & $0.1-5$ & $0.1-5$ & $0.1-5$ & $0.1-5$ & $1-50$ \\
\hline $\begin{array}{l}\text { Determination } \\
\text { coefficient (r2) }\end{array}$ & 0.9998 & 0.9998 & 0.9998 & 0.9998 & 0.9998 \\
\hline $\mathrm{CC} \alpha$ & $4.32 \%$ & $3.84 \%$ & $4.55 \%$ & $3.95 \%$ & $3.87 \%$ \\
\hline
\end{tabular}

CC $\alpha$-Decision limit (max. allowed 5\%).

the combined standard solution of AflB1, AflB2, AflG1, AflG2, and OchA to the decarboxylated oil.

\section{Experimental Design}

At the beginning of the experiment, the concentration of AfB1, AfB2, AfG1, AfG2, and Och A in dry cannabis flowers (we use a variety of Herijuana) was determined. Then, AfB1, AfB2, AfG1, AfG2 $(2 \mu \mathrm{g} / \mathrm{kg})$, and Och A $(20 \mu \mathrm{g} / \mathrm{kg})$ were added to $250 \mathrm{~g}$ dried cannabis flowers, which were divided into three equal portions $2 \mathrm{~h}$ after adding of mycotoxins. The maceration was performed with $96 \%$ ethanol as a solvent, in a cold chamber (refrigerator at $-20^{\circ} \mathrm{C}$ ). The duration of the maceration was $30 \mathrm{~min}$ in total. Each portion of cannabis flowers was macerated in approximately $415 \mathrm{ml}$ of $96 \%$ ethanol for $10 \mathrm{~min}$ separately (in total, $1.25 \mathrm{~L}$ of $96 \%$ ethanol was used for maceration). Stirring by stainless steel spoon was done on portion every 2 min. After maceration was completed, the macerated material (cannabis flowers) was manually squeezed with a stainless-steel strainer. The resulting macerate was filtered and collected in a pre-measured 1L beaker. The ethanol was evaporated on a hot plate. After evaporation of the ethanol, the obtained crude oil was decarboxylated by heating until the temperature of the crude extract reached $125-130^{\circ} \mathrm{C}$. The experiment was performed three times (Batch No. RS0221/1, Batch No. RS0221/2, Batch No. RS0221/3).

\section{RESULTS}

\section{Validation of the Method}

The calibration characteristics and validation parameters of the proposed method are shown in Table 3 and Figure 4. Linearity of response was calculated as a ratio of peak areas of AflB1, AflB2, AflG1, AflG2, and OchA vs. concentration in the spiked samples in the concentration range of $0.1-5 \mu \mathrm{g} / \mathrm{L}$ in 50:50 water: methanol with $0.1 \%$ formic acid for AflB1, AflB2, AflG1, and AflG2 and OchA from 1-50 $\mu \mathrm{g} / \mathrm{L}$ in 50:50 water: methanol with $0.1 \%$ formic acid. The correlation coefficient was $>0.999$ for all mycotoxins.

The limit of detection (DL)/ limit of quantification (QL) was determined based on the formulas: $\mathrm{DL}=3,3 \times \sigma / \mathrm{S}$ and $\mathrm{QL}=$ $10 \mathrm{x} \sigma / \mathrm{S}$, where $\sigma$ is the SD of the response and $\mathrm{S}$ is the slope of the calibration curve. The DL/QL for each mycotoxin separately is shown in Table 4.

Figure 4 shows the calibration curve of AfG2 (4-a), the calibration curve of AfG1 (4-b), the calibration curve of AfB2 (4c), the calibration curve of AfB1 (4-d), and the calibration curve of OchA (4-e). 

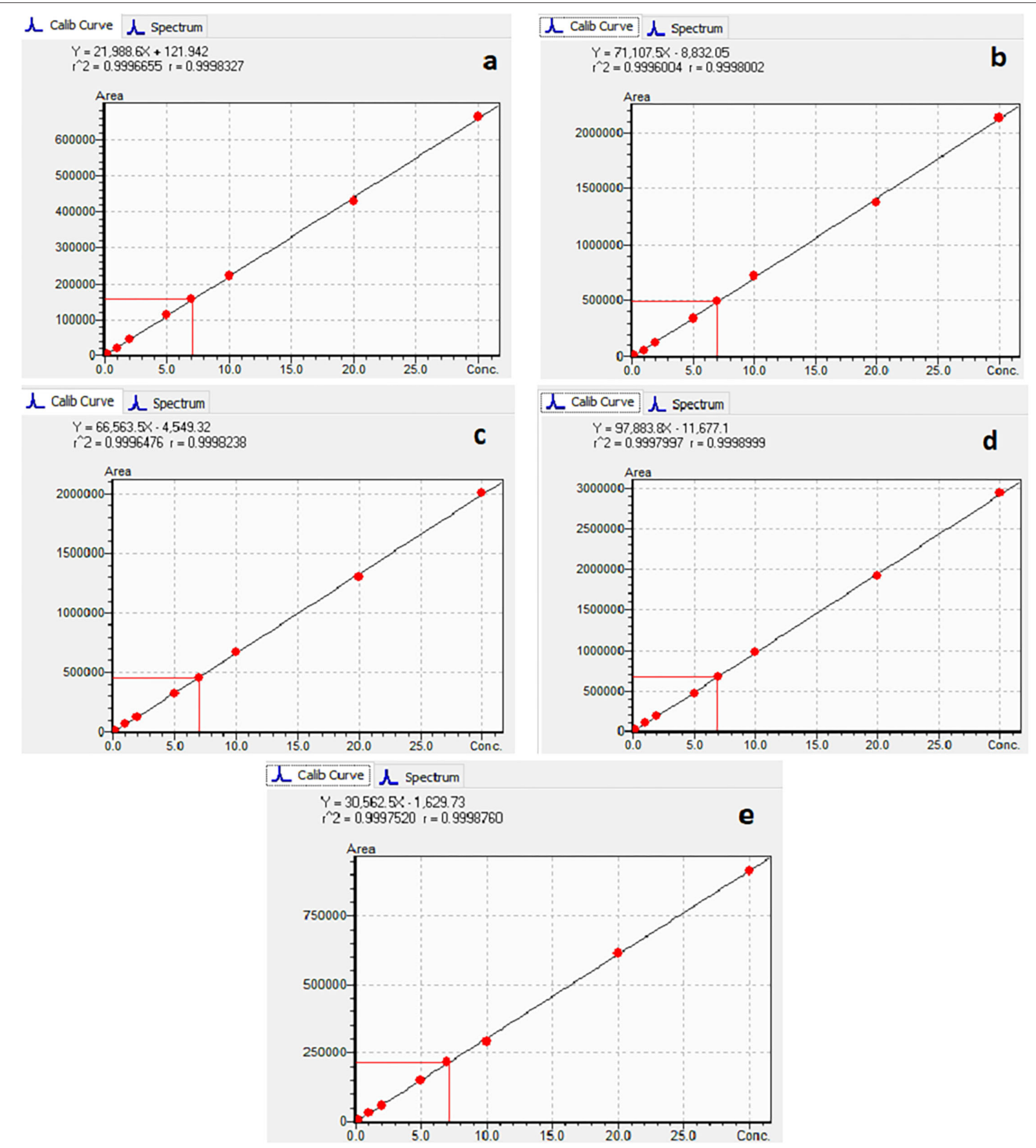

FIGURE 4 | Calibration curves of AfG2 (a), AfG1 (b), AfB2 (c), AfB1 (d), OchA (e).

The results of precision, accuracy (recovery), and reproducibility (assay) of the method are shown in Table 5. They demonstrate good precision determined as the relative standard deviation (\%RSD) accuracy, and reproducibility. RSD is the absolute value of the coefficient of variation and indicates whether the "regular" SD is a small or large quantity when compared to the mean for the data set.

The matrix effect was evaluated using the post-extraction spike method, by adding standard solutions of mycotoxins into the matrix after extraction. Calibration curves of standard solutions of mycotoxins and spiked standard solutions of 
TABLE 4 | Precision and accuracy of the method.

\begin{tabular}{|c|c|c|c|c|}
\hline \multirow[t]{3}{*}{ Concentration added $(\mu \mathrm{g} / \mathrm{L})$} & \multicolumn{4}{|c|}{ Measured concentration $(\mu \mathrm{g} / \mathrm{L})^{a}$} \\
\hline & \multicolumn{2}{|c|}{ AfG2 } & \multicolumn{2}{|c|}{ AfG1 } \\
\hline & Mean $(\mu \mathrm{g} / \mathrm{L}) \pm \mathrm{RSD}(\%)$ & Recovery (\%) & Mean $(\mu \mathrm{g} / \mathrm{L}) \pm \mathrm{RSD}(\%)$ & Recovery (\%) \\
\hline 1.5 & $1.215 \pm 0.96$ & 81.0 & $1.214 \pm 0.58$ & 80.9 \\
\hline 2.0 & $1.892 \pm 0.82$ & 94.6 & $1.940 \pm 0.82$ & 97.0 \\
\hline 5.0 & $4.321 \pm 0.78$ & 86.42 & $4.696 \pm 0.85$ & 93.9 \\
\hline \multirow[t]{3}{*}{ Concentration added $(\mu \mathrm{g} / \mathrm{L})$} & \multicolumn{4}{|c|}{ Measured concentration $(\mu \mathrm{g} / \mathrm{L})^{a}$} \\
\hline & \multicolumn{2}{|c|}{ AfB2 } & \multicolumn{2}{|c|}{ AfB1 } \\
\hline & Mean $(\mu \mathrm{g} / \mathrm{L}) \pm \mathrm{RSD}(\%)$ & Recovery (\%) & Mean $(\mu \mathrm{g} / \mathrm{L}) \pm \mathrm{RSD}(\%)$ & Recovery (\%) \\
\hline 1.5 & $1.228 \pm 0.87$ & 81.86 & $1.334 \pm 0.71$ & 88.93 \\
\hline 2.0 & $1.927 \pm 0.58$ & 96.35 & $1.938 \pm 0.49$ & 96.9 \\
\hline 5.0 & $4.283 \pm 0.72$ & 85.66 & $4.900 \pm 0.57$ & 98.0 \\
\hline \multirow[t]{3}{*}{ Concentration added $(\mu \mathrm{g} / \mathrm{L})$} & \multicolumn{4}{|c|}{ Measured concentration $(\mu \mathrm{g} / \mathrm{L})^{\mathrm{a}}$} \\
\hline & \multicolumn{2}{|c|}{ OchA } & & \\
\hline & Mean $(\mu \mathrm{g} / \mathrm{L}) \pm \mathrm{RSD}(\%)$ & Recovery (\%) & & \\
\hline 15 & $14.09 \pm 0.86$ & 93.93 & & \\
\hline 20 & $20.93 \pm 0.93$ & 104.6 & & \\
\hline 50 & $50.59 \pm 1.03$ & 101.18 & & \\
\hline
\end{tabular}

${ }^{a}$ Mean value of five determinations.

TABLE 5 | Limit of detection/Limit of quantification for AflB1, AflB2, AflG1, AflG2, and OchA.

\begin{tabular}{lcc}
\hline Mycotoxin & Limit of detection $(\boldsymbol{\mu} \mathbf{g} / \mathbf{k g})$ & Limit of quantification $(\boldsymbol{\mu} \mathbf{g} / \mathbf{k g})$ \\
\hline AfIG2 & 0,023 & 0,069 \\
AflG1 & 0,017 & 0,053 \\
AflB2 & 0,034 & 0,105 \\
AflB1 & 0,027 & 0,082 \\
OchA & 0,329 & 0,997 \\
\hline
\end{tabular}

mycotoxins in the matrix were evaluated. It was shown that co-eluting compounds from the matrix affect the ionization efficiency and reproducibility in the ionization source (Figure 5). Therefore, all analyzes were evaluated using matrix calibration curves.

Figure 6 shows the typical chromatogram and analyte transitions of AfG2 (5-a), the typical chromatogram and analyte transitions of AfG1 (5-b), the typical chromatogram and analyte transitions of AfB2 (5-c), the typical chromatogram and analyte transitions of AfB1 (5-d), and the typical chromatogram and analyte transitions of OchA (5-e).

\section{Calculation of AfIB1, AfIB2, AfIG1, AfIG2, and OchA in Experimental Design}

The concentration of aflatoxins and OchA were determined using the same LC/MS/MS analytical method in the starting material (dry flower) before spike and in obtained decarboxylated extract after extraction with ethanol 96\%. The content of AflB1, AflB2, AflG1, AflG2, and OchA in microgram per kilogram of cannabis flower variety Herijuana (Table 6) and cannabis extracts (Table 7) obtained from cannabis flowers spiked with maximum residual level (MRL) allowed for aflatoxins $(2 \mu \mathrm{g} / \mathrm{kg})$ and $(20$ $\mu \mathrm{g} / \mathrm{kg}$ ) for OchA was calculated separately for each mycotoxin.

The results of the assay in the not-spiked dry flowers (Table 6) show that there are no significant quantities of mycotoxins that could influence the validity of the experiment.

From the percent presented in Table 7, we can conclude that after evaporation of the solvent, aflatoxins, and OchA, remain in the final extract in amounts much higher than those in which the same are added.

Figure 7 shows the chromatogram of cannabis extract obtained from cannabis flowers spiked with MRL for aflatoxins $(2 \mu \mathrm{g} / \mathrm{kg})$ and OchA $(20 \mu \mathrm{g} / \mathrm{kg})$.

\section{DISCUSSION}

Medical or recreational use of cannabis is now legal in more than 50 countries all over the world. With this emerging interest in cannabis, as governments regulate this field, there is an urgent need to understand possible contaminations and how this could impact human safety and health $(25,26)$. This is of particular concern for people who have compromised immune systems and use cannabis for medicinal purposes (26). 


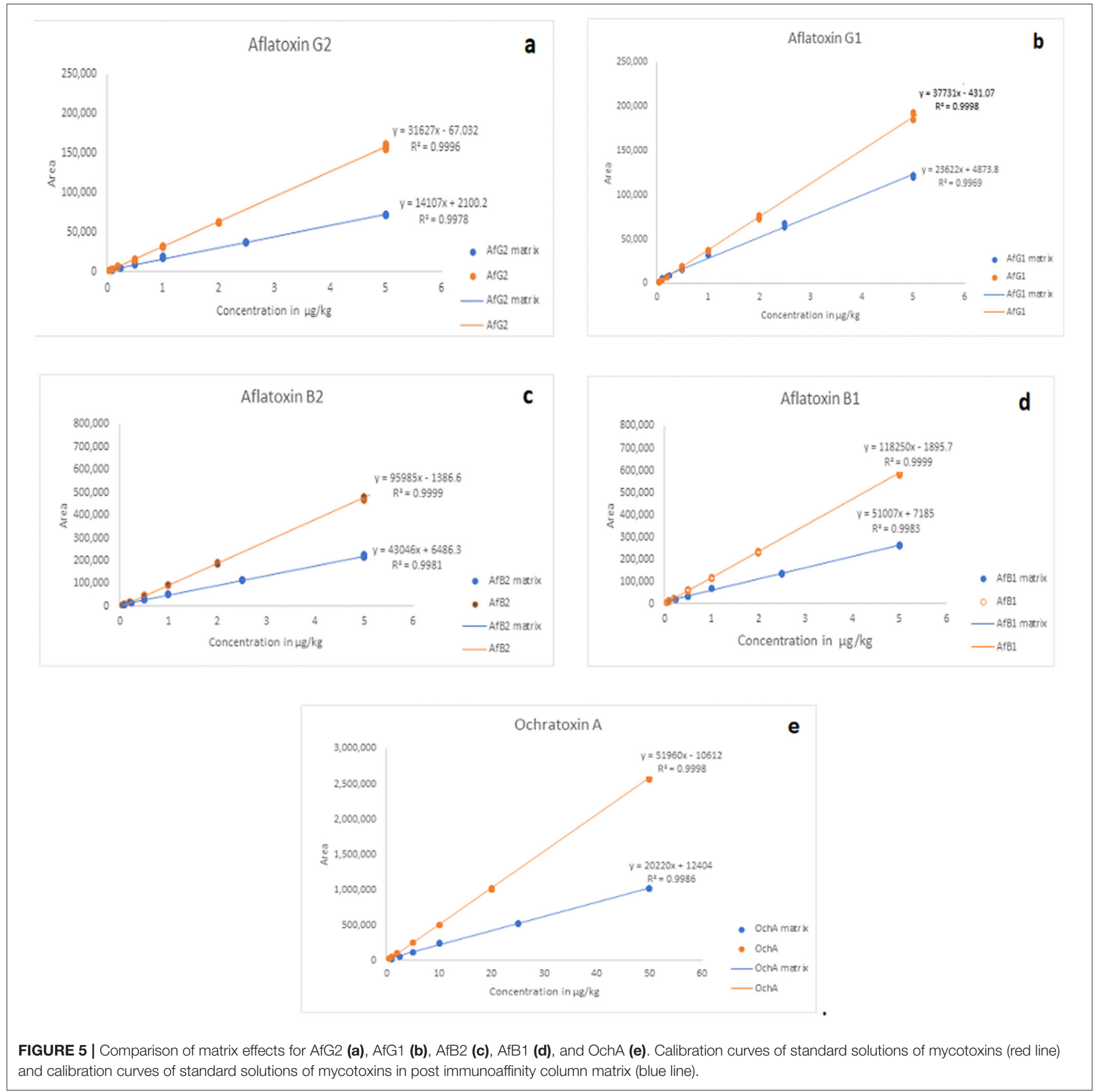

In this study, we analyze the connection between cannabis cultivation and mycotoxins outcomes. Aflatoxins become especially problematic if the drying and storage of cannabis flowers are inappropriate (27).

Cannabis preparations are widespread products used to treat various painful and pathogenic conditions. The use of these preparations has been increasing in the last 10 years. Aflatoxins are a major source of disease, therefore, the extreme levels of aflatoxins in cannabis herbal preparations are of major concern. Post-harvest treatments to remove aflatoxins such as alkalization, ammonization, and heat or gamma radiation are not generally used and proposed. The M1 and M2 metabolic derivatives of AflB1 and AflB2 can be also excreted out through milk (9), and there could be a possibly harmful effect on breastfed infants.

Mycotoxins, especially aflatoxins, are extremely toxic secondary metabolites. They can cause disease and death in humans. Aflatoxins (Ph.Eur. 2.8.18) are limited to $\leq 2 \mu \mathrm{g} / \mathrm{kg}$ for AfB1 and total aflatoxins (AflB1, AflB2, AflG1, AflG2) $\leq 4$ $\mu \mathrm{g} / \mathrm{kg}$. OchA (Ph.Eur 2.8.22) is limited to $\leq 20 \mu \mathrm{g} / \mathrm{kg}$ (5).

Standardized concentrated cannabinoid extracts, which are obtained from cannabis flowers, are used as a raw material for the preparation of cannabis products for human use. The 


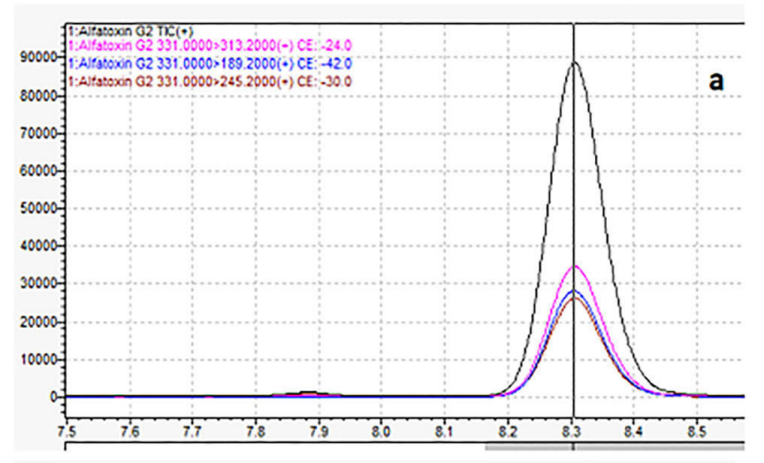

$\lambda$ cosbcare $\mathcal{L}$ saxtrom

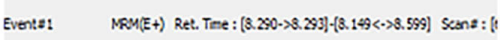

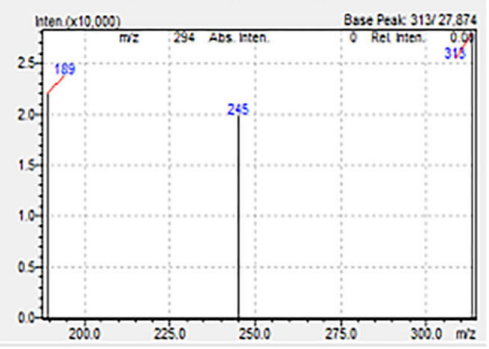

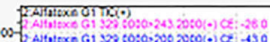

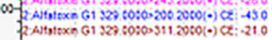
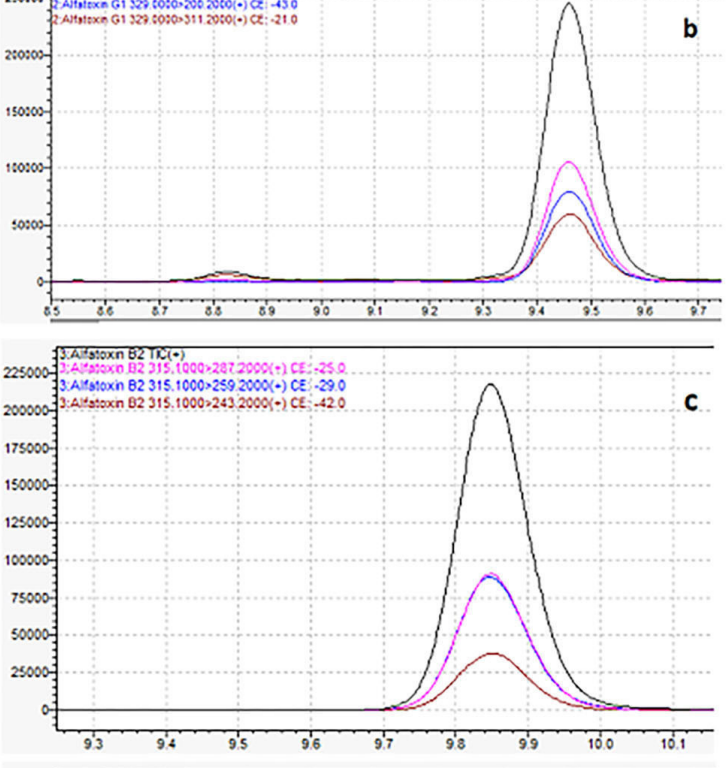

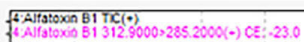
f. Attatoxon B1 $313.0000 \times 241.2000$ (*) CE: -35.0

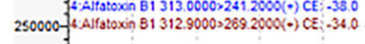
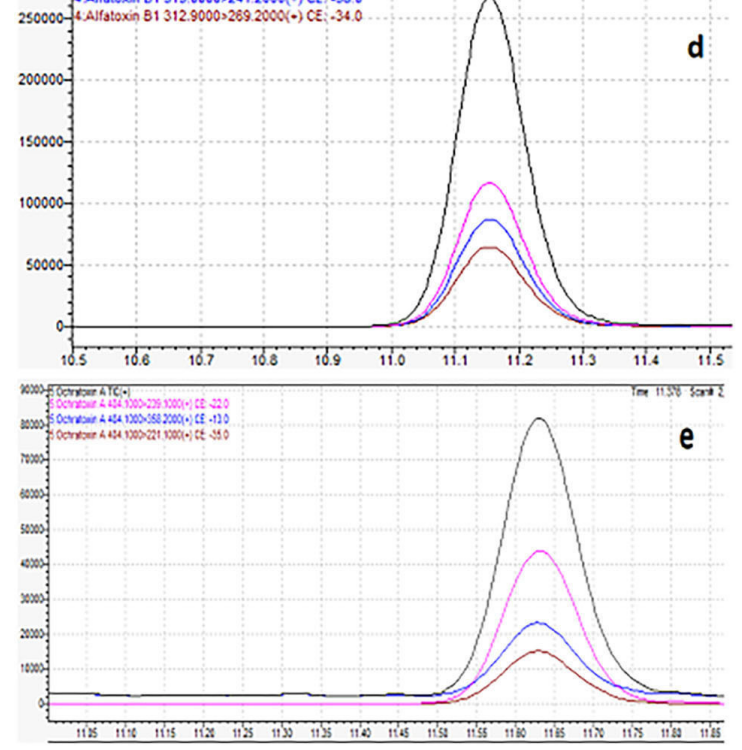

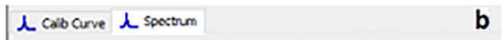

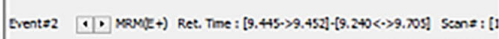

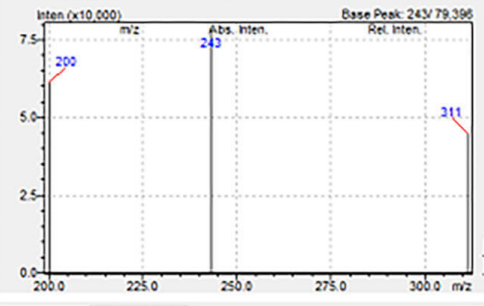

$\lambda$ costocure $\lambda$ sostum

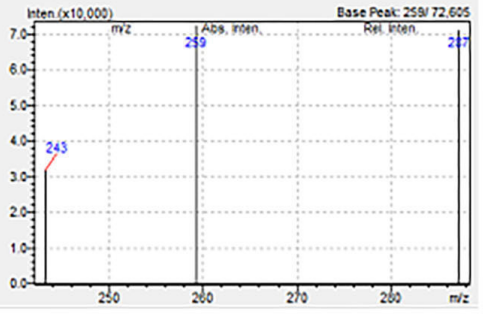

$\Lambda$ colbane $\mathcal{L}$ soectrun

d

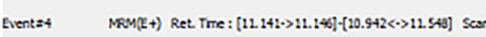

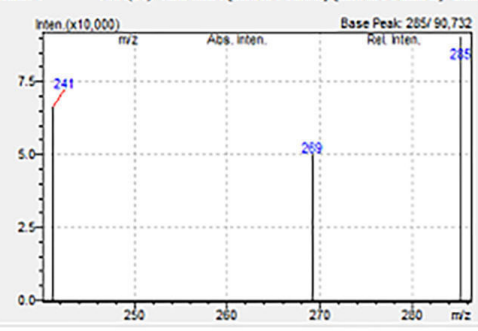

$\Lambda$ cobane $\ell$ soectun

e

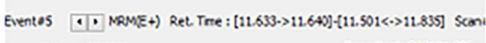

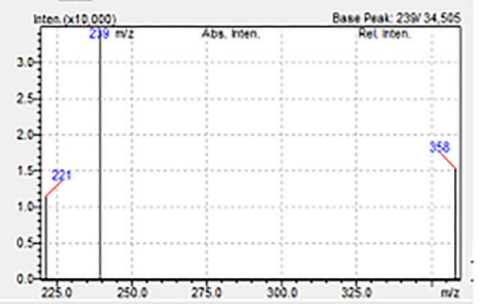

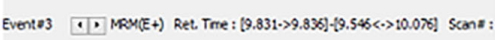

FIGURE 6 | Typical chromatogram and analyte transitions of the of AfG2 (a), AfG1 (b), AfB2 (c), AfB1 (d), OchA (e). 
extraction process is usually made by supercritical $\mathrm{CO}_{2}$ or ethanol $(28,29)$.

Ethanol, according to Ph.Eur., is classified as a Class 3 solvent with a low risk for acute or chronic toxicity in pharmaceutical manufacturing processes where the residual is $<5,000 \mathrm{ppm}$ $(0.5 \%)$ (5). Ethanol is a very good solvent for the extraction of cannabinoids and terpenes and, at the same time, a very good solvent for mycotoxins. Extraction can be conducted under warm (room temperature) or cold conditions (supercooled ethanol extraction). The difference is that at room temperature generally more waxes and pigments are extracted which results in additional clarification steps than supercooled techniques. To extract the solutes from the flowers, ethanol must completely saturate the flowers. Therefore, a significant volume of ethanol is needed to perform the process with an efficiency rate of more than $90 \%$ (24). In our case, we use ethanol $96 \%$ in ratio flowers: ethanol $=1: 5$.

TABLE 6 | The content of Aflatoxin B1, B2, G1, G2, and Ochratoxin A in cannabis dry flower variety Herijuana Batch No. 01012101 before spike.

Content of mycotoxins in cannabis dry $(\mu \mathrm{g} / \mathrm{kg})$

\begin{tabular}{ll}
\hline AfG2 & Not detected \\
AfG1 & Not detected \\
AfB2 & Not detected \\
AfB1 & Not detected \\
OchA & Not detected
\end{tabular}

A novel sensitive, reproducible, rapid, and cost-effective LC/MS/MS method for the determination of aflatoxins and OchA was developed and validated. Recent trends of development in the methods of sample extraction, cleanup processes, detection technologies, quantitative methods, and the current research of fast and noninvasive detection methods were followed (8).

The flowers used for extraction were spiked with the maximum permitted level of mycotoxins according to Ph.Eur. (2.8.18 and 2.8.22) (5). Considering that AfB1 is limited to $\leq 2 \mu \mathrm{g} / \mathrm{kg}$, means that every other mycotoxin (AfB2, AfG1, AfG2), individually, can be found in the flowers in the amount $\leq 2 \mu \mathrm{g} / \mathrm{kg}$ (assuming no presence of another aflatoxin), which means not to exceed the limit of total allowed mycotoxins $\leq 4$ $\mu \mathrm{g} / \mathrm{kg}$. After evaporation of ethanol and decarboxylation process of crude, the content of mycotoxins was determined by the LC/MS/MS method.

The results obtained indicate that aflatoxins and OchA, although well soluble in ethanol, after evaporation of the solvent, remain in the final extract in an amount much higher than the amount in which we added them. If we consider that during the extraction the sample is concentrated (from $250 \mathrm{~g}$ of flowers, we obtained $16 \mathrm{~g}$ of extract), it means that the level of aflatoxins and OchA in the final extract is much higher than the maximum allowed level according to the Ph.Eur. (5), thus, posing a risk to human safety and health (determined percentage from the maximum allowed concentration: $301-345.5 \%$ for AfG2, 316$345 \%$ for AfG1, 243-255\% for AfB2, 229.5-253\% for AfB1, and $599.5-708 \%$ for OchA).

TABLE 7 | The content of Aflatoxin B1, B2, G1, G2 and Ochratoxin A in cannabis extract obtained from cannabis flowers spiked with maximum allowed residual level for aflatoxins and ochratoxin $A$.

\begin{tabular}{|c|c|c|c|c|c|c|}
\hline & RS0221/1 & & RS0221/2 & & RS0221/3 & \\
\hline \multicolumn{7}{|l|}{ AfG2 } \\
\hline \multirow{2}{*}{$\begin{array}{l}\text { Added in flowers } 2 \\
\mu \mathrm{g} / \mathrm{kg}\end{array}$} & Determined in extract $(\mu \mathrm{g} / \mathrm{kg})$ & $(\%)$ & Determined in extract $(\mu \mathrm{g} / \mathrm{kg})$ & $(\%)$ & Determined in extract $(\mu \mathrm{g} / \mathrm{kg})$ & $(\%)$ \\
\hline & 6.91 & 345.5 & 6.02 & 301.0 & 6.122 & 306.1 \\
\hline \multicolumn{7}{|l|}{ AfG1 } \\
\hline \multirow{2}{*}{$\begin{array}{l}\text { Added in flowers } 2 \\
\mu \mathrm{g} / \mathrm{kg}\end{array}$} & Determined in extract $(\mu \mathrm{g} / \mathrm{kg})$ & $(\%)^{*}$ & Determined in extract $(\mu \mathrm{g} / \mathrm{kg})$ & $(\%)^{*}$ & Determined in extract $(\mu \mathrm{g} / \mathrm{kg})$ & $(\%)^{\star}$ \\
\hline & 6.90 & 345.0 & 6.32 & 316.0 & 6.42 & 321.0 \\
\hline \multicolumn{7}{|l|}{ AfB2 } \\
\hline \multirow{2}{*}{$\begin{array}{l}\text { Added in flowers } 2 \\
\mu \mathrm{g} / \mathrm{kg}\end{array}$} & Determined in extract $(\mu \mathrm{g} / \mathrm{kg})$ & $(\%)^{\star}$ & Determined in extract $(\mu \mathrm{g} / \mathrm{kg})$ & $(\%)^{\star}$ & Determined in extract $(\mu \mathrm{g} / \mathrm{kg})$ & $(\%)^{\star}$ \\
\hline & 5.1 & 255.0 & 4.86 & 243.0 & 4.90 & 245.0 \\
\hline \multicolumn{7}{|l|}{ AfB1 } \\
\hline \multirow{2}{*}{$\begin{array}{l}\text { Added in flowers } 2 \\
\mu \mathrm{g} / \mathrm{kg}\end{array}$} & Determined in extract $(\mu \mathrm{g} / \mathrm{kg})$ & $(\%)^{\star}$ & Determined in extract $(\mu \mathrm{g} / \mathrm{kg})$ & $(\%)^{\star}$ & Determined in extract $(\mu \mathrm{g} / \mathrm{kg})$ & $(\%)^{\star}$ \\
\hline & 5.06 & 253.0 & 4.59 & 229.5 & 4.62 & 231.0 \\
\hline \multicolumn{7}{|l|}{ OchA } \\
\hline \multirow{2}{*}{$\begin{array}{l}\text { Added in flowers } 20 \\
\mu \mathrm{g} / \mathrm{kg}\end{array}$} & Determined in extract $(\mu \mathrm{g} / \mathrm{kg})$ & $(\%)^{\star}$ & Determined in extract $(\mu \mathrm{g} / \mathrm{kg})$ & $(\%)^{*}$ & Determined in extract $(\mu \mathrm{g} / \mathrm{kg})$ & $(\%)^{\star}$ \\
\hline & 141.6 & 708.0 & 119.9 & 599.5 & 121.9 & 609.5 \\
\hline
\end{tabular}

*Percentage from the maximum allowed concentration. 


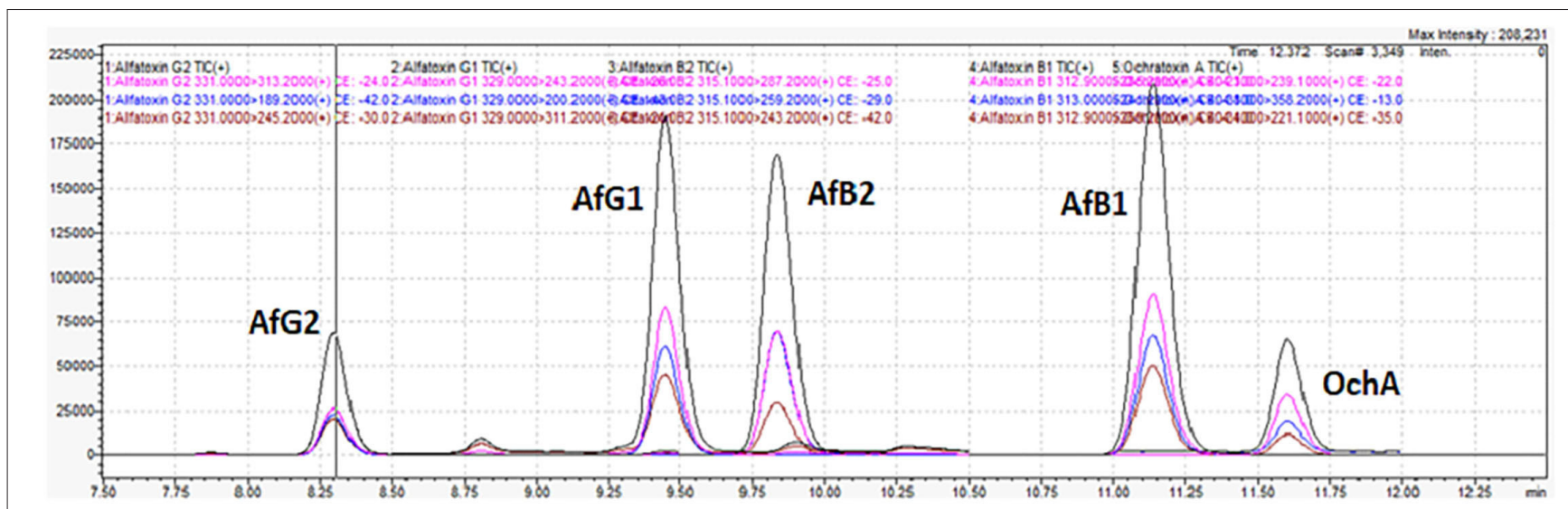

FIGURE 7 | Chromatogram of cannabis extract obtained from cannabis floss spiked with MRL for aflatoxins (2 $\mu \mathrm{g} / \mathrm{kg})$ and ochratoxin A (20 $\mu \mathrm{g} / \mathrm{kg})$.

Therefore, it is very important that cannabis cultivation and post-harvest treatment including storage is performed under controlled conditions to avoid the formation of mycotoxins. In this way, human health can be protected and well preserved (25).

\section{CONCLUSION}

Emerging interest in cannabis-based preparation for medicinal use has imposed an urgent need to understand possible contaminations, referring especially to the effect of aflatoxins which are extremely toxic secondary metabolites. These may pass from the contaminated plant material to the extract and have an impact on human safety and health. To demonstrate this, a novel sensitive, reproducible, rapid, and cost-effective LC/MS/MS method for the determination of aflatoxins and OchA in cannabis extracts was developed and validated. The results obtained from the testing indicate that aflatoxins and OchA, primarily added to the cannabis dried flowers, were also present in the obtained final extract, in amounts higher $(\mathrm{m} / \mathrm{m})$ than those in starting plant material. With this experiment, we have shown that aflatoxins as extremely toxic secondary metabolites, can reach critical values in cannabis extracts obtained from dry cannabis flowers with the maximum allowed quantity of

\section{REFERENCES}

1. Russo EB. History of cannabis and its preparations in saga, science, and sobriquet. Chem Biodivers. (2007) 4:1614-48. doi: 10.1002/cbdv.200790144

2. Casiraghi G, Roda E, Casagni C, Cristina U, Musazzi M, Franzè S, et al. Extraction method and analysis of cannabinoids in cannabis olive oil preparations. Planta Medica. (2018) 84:242-9. doi: 10.1055/s-0043123074

3. German Pharmacopoeia 2018 (DAB 2018). Monograph Cannabisblüten and Monograph Eingestellter Cannabisextrakt, published in the (German) Bundesanzeiger: Cologne (2018).

4. EU-Guideline. 83 Consolidated Version, Annex I EG. Luxembourg: Publications Office of the European Union 2001 (2001). Available online at: https://eur-lex.europa.eu/LexUriServ/LexUriServ.do?uri=CONSLEG: 2001L0083:20110721:EN:PDF (accessed June 04, 2021). aflatoxins. This can pose a great risk to consumers and their health especially to those with compromised immune systems.

\section{DATA AVAILABILITY STATEMENT}

The original contributions presented in the study are included in the article/supplementary material, further inquiries can be directed to the corresponding author/s.

\section{AUTHOR CONTRIBUTIONS}

All authors listed have made a substantial, direct and intellectual contribution to the work, and approved it for publication.

\section{ACKNOWLEDGMENTS}

The authors are grateful to the management of NYSK Holdings (part of Pharmacann International Group, Poland) for enabling this research to be done in their laboratory for quality control of cannabis flowers and cannabis extracts. The authors want to thank all the employers in NYSK Holdings that have contributed to this research. 
10. Manal M, Zaki S, El-Midany A, Shaheen HM, Rizzi L. Mycotoxins in animals: Occurrence, effects, prevention and management. J Toxicology and Environmental Health Sciences. (2012) 4:13-28.

11. Zhang Z, Nie D, Fan K, Yang, Guo W, Meng J, et al. A systematic review of plant-conjugated masked mycotoxins: Occurrence, toxicology, and metabolism. Crit Rev Food Sci Nutr. (2020). 60:1523-37. doi: 10.1080/10408398.2019.1578944

12. International Agency for Research on Cancer (IARC). Some Naturally Occurring Substances: Food Items and Constituents, Heterocyclic Aromatic Amines and Mycotoxins. Lyon: IARC (1993).

13. World Health Organization \& Joint FAO/WHO Expert Committee on Food Additives. Evaluation of Certain Contaminants in food: Eighty-Third Report of the Joint FAO/WHO Expert Committee on Food Additives. World Health Organization Technical Report Series. Geneva: World Health Organization (2017).

14. Norbäck D, Hashim JH, Cai GH, Hashim Z, Ali F, Bloom E, et al. Rhinitis, ocular, throat and dermal symptoms, headache and tiredness among students in schools from Johor Bahru, Malaysia: associations with fungal DNA and mycotoxins in classroom Dust. PLOS ONE. (2016). 11:e0147996. doi: 10.1371/journal.pone.0147996

15. Al-Jaal BA, Jaganjac M, Barcaru A, Horvatovich P, Latiff A. Aflatoxin, fumonisin, ochratoxin, zearalenone and deoxynivalenol biomarkers in human biological fluids: A systematic literature review, 2001-2018. Food Chem Toxicol. (2019) 129:211-28. doi: 10.1016/j.fct.2019.04.047

16. International Agency for Research on Cancer (IARC) Improving Public Health through Mycotoxin Control. In: Pitt JI, Wild CP, Baan RA, Gelderblom WCA, Miller J, Riley RT, Wu F, editors. Lyon: IARC (2012).

17. $\mathrm{Li} \mathrm{S}, \mathrm{Zhou} \mathrm{J,} \mathrm{Xu} \mathrm{S}, \mathrm{Li} \mathrm{J}$, Liu J, $\mathrm{Lu} \mathrm{Y}$, et al. Induction of $\mathrm{Nrf2}$ pathway by Dendrobium nobile Lindl. Alkaloids protects against carbon tetrachloride induced acute liver injury. Biomed Pharmacother. (2019) 117:109073. doi: 10.1016/j.biopha.2019.109073

18. Damiano S, Longobardi C, Andretta E, Prisco F, Piegari G, Squillacioti C, et al. Antioxidative effects of curcumin on the hepatotoxicity induced by ochratoxin a in rats. Antioxidants. (2021) 10:125. doi: 10.3390/antiox10010125

19. Damiano S, Iovane V, Squillacioti C, Mirabella N, Prisco F, Ariano A, et al. Red orange and lemon extract prevents the renal toxicity induced by ochratoxin $\mathrm{A}$ in rats. J Cell Physiol. (2020) 235:5386-93. doi: 10.1002/jcp.29425

20. Zhu L, Yu T, Qi X, Gao J, Huang K, He X, et al. Limited link between oxidative stress and ochratoxin A-Induced renal injury in an acute toxicity rat model. Toxins. (2016) 8:373. doi: 10.3390/toxins 8120373

21. Wilcox J, Pazdanska M, Milligan C, Chan D, MacDonald SJ, Donnelly C. Analysis of aflatoxins and ochratoxin A in Cannabis and Cannabis Products by LC-fluorescence detection using cleanup with either multiantibody immunoaffinity columns or an automated system with in-line reusable immunoaffinity cartridges. J AOAC Int. (2020) 103:494-503. doi: 10.5740/jaoacint.19-0176

22. López-Ruiz R, Marín-Sáez J, Garrido Frenich A, Romero-González R. Recent Applications of Chromatography for Analysis of Contaminants in Cannabis Products: A Review. Wiley Online Library (2021). doi: 10.1002/ps.6599

23. 2002/657/EC: Commission Decision of 12 August 2002 implementing Council Directive $96 / 23 /$ EC concerning the performance of analytical methods and the interpretation of results (Text with EEA relevance) (notified under document number C 3044) p. 8-36.

24. ICH (2002). Guideline on Analytical Method Validation. Toronto, Canada: Proceeding of International Convention on Quality for the Pharmaceutical Industry.

25. Wartenberg AC, Holden PA, Bodwitch H, Parker-Shames P, Novotny T, Harmon TC, et al. Cannabis and the Environment: What Science Tells Us and What We Still Need to Know. Environ Sci Technol Lett. (2021) 8:98107. doi: 10.1021/acs.estlett.0c00844

26. Zackary M, Matthieu C, Vanden Heuvel Brian D, Pauli Christopher S, Sang-Hyuck P. Cannabis Contaminants Limit Pharmacological Use of Cannabidiol. Front Pharmacology. (2020). 11:1439. doi: 10.3389/fphar.2020.5 71832

27. Mcpartland JM, Mckernan KJ. Contaminants of concern in cannabis: microbes, heavy metals and pesticides in cannabis sativa L. - Botany and Biotechnology. Chandra S, Lata H, Elsohly MA, editors. Cham: Springer International Publishing. (2017) 457-74. doi: 10.1007/978-3-319-545 64-6_22

28. Daniel G, Ignacio V, Lucio F. Supercritical extraction strategies using CO2 and ethanol to obtain cannabinoid compounds from cannabis hybrid flowers. Journal of CO2 Utilization. (2019). 30:174-80. doi: 10.1016/j.jcou.2018. 12.014

29. Mark June-Wells. Your Guide to Ethanol Extraction in Cannabis. Cannabis Business Times (2018). Available online at: https://www. cannabisbusinesstimes.com/article/your-guide-to-ethanol-extraction/ (accessed Jun 04, 2021).

Conflict of Interest: JE is employed by Diapharm GmbH \& Co. KG, Münster, Germany. SS, ZK, and MM are employed by NYSK Holdings, Company for growing, extraction and producing of pharmaceutical dosage forms of medical cannabis, Skopje, North Macedonia.

The remaining authors declare that the research was conducted in the absence of any commercial or financial relationships that could be construed as a potential conflict of interest.

Publisher's Note: All claims expressed in this article are solely those of the authors and do not necessarily represent those of their affiliated organizations, or those of the publisher, the editors and the reviewers. Any product that may be evaluated in this article, or claim that may be made by its manufacturer, is not guaranteed or endorsed by the publisher.

Copyright (C) 2021 Serafimovska, Stefanovski, Erler, Keskovski, Stefkov, Mitevska, Darkovska Serafimovska, Balkanov and Tonic Ribarska. This is an open-access article distributed under the terms of the Creative Commons Attribution License (CC $B Y)$. The use, distribution or reproduction in other forums is permitted, provided the original author(s) and the copyright owner(s) are credited and that the original publication in this journal is cited, in accordance with accepted academic practice. No use, distribution or reproduction is permitted which does not comply with these terms. 